\title{
When best evidence is rarer than the disease
}

\author{
Gregory C. Allen, MD
}

Received: 11 June 2013/Accepted: 30 July 2013/Published online: 8 October 2013

(C) Canadian Anesthesiologists' Society 2013

\section{To the Editor,}

Dr. Bryson raises important questions in his editorial, "Rarity and review: evidence-based practice for uncommon diseases". ${ }^{1}$ For many rare disorders, such as carcinoid heart disease, "Best Evidence" is a case series that took 18 years to assemble!

Animal models of rare diseases provide another source of evidence. ${ }^{2}$ The porcine model of malignant hyperthermia $(\mathrm{MH})$ has been used to develop human diagnostic tests and showed the efficacy of dantrolene therapy at a time when human MH mortality was $80 \% .^{3}$ Most of what we know about MH comes from such studies and from epidemiologic work. There will never be a human randomized controlled trial (RCT) to determine the optimal dose of dantrolene to treat MH. Instead, $\mathrm{MH}$ in susceptible swine was considered similar enough to human $\mathrm{MH}$ to extrapolate those results with dramatic effect on mortality. Now new ex vivo models, such as tissue myotubes or cell cultures, provide functional assays to study $\mathrm{MH}$ pathophysiology and therapeutics. ${ }^{4,5}$

The Oxford Centre for Evidence-Based Medicine (OCEBM) Levels of Evidence (2011) and the PRISMA statement, cited by Dr. Bryson, are silent on such nonclinical studies. The OCEBM lists systematic review of human RCTs as an example of Level 1 evidence but describes "mechanism-based reasoning" as the lowest level (Level 5). It does not dismiss such weaker evidence, but it does not specify how it should be evaluated.

Recently, the United States Agency for Healthcare Research and Quality (AHRQ) released a white paper outlining a framework to evaluate "the evidential weight of

G. C. Allen, MD ( $₫)$

Olympia Anesthesia Associates, Olympia, WA, USA

e-mail: gallen57@yahoo.com mechanistic knowledge". A It provides a definition of evidence based on inferential effect (how things work), not study design (how information was produced), as is the case in evidence-based medicine (EBM). It suggests that the strength of inferential evidence is "represented by the degree to which the probability of a clinical effect is modified by evidence from the component steps". Those steps are a formalized evaluation of mechanistic evidence that includes seeking a "translation" step that significantly raises the probability that the evidence could be applied to humans. Pharmaceutical companies already practice in a similar way to bring new compounds to market. The AHRQ considers that such a framework could link basic science, EBM, and comparative effectiveness research. The translation of evidence from such mechanistic knowledge could help strengthen systematic reviews of rare disorders.

Conflicts of interests None declared.

\section{References}

1. Bryson GL. Rarity and review: evidence-based practice for uncommon diseases. Can J Anesth 2013; 60: 419-22.

2. Jackson LN, Chen LA, Larson SD, et al. Development and characterization of a novel in vivo model of carcinoid syndrome. Clin Cancer Res 2009; 15: 2747-55.

3. Harrison GG. Control of malignant hyperpyrexic syndrome in MHS swine by dantrolene sodium. Br J Anaesth 1975; 47: 62-5.

4. Sato K, Pollock N, Stowell KM. Functional studies of RYR1 mutations in the skeletal muscle ryanodine receptor using human RYR1 complementary DNA. Anesthesiology 2010; 112: 1350-4.

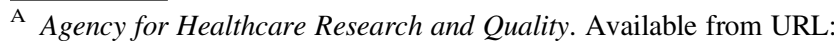
http://www.effectivehealthcare.ahrq.gov/search-for-guides-reviewsand-reports/?pageaction=displayproduct\&productID=1553 (accessed June 2013).
} 
5. Dowling JJ, Arbogast S, Hur J, et al. Oxidative stress and successful antioxidant treatment in models of RYR1-related myopathy. Brain 2012; 135: 1115-27.

\section{Reply}

Thank you, Dr. Allen, for drawing readers' attention to the importance of basic science research in clinical medicine. The white paper $^{1}$ released by the Agency for Healthcare Research and Quality (AHRQ) describes a framework within which mechanistic data from animal models may be integrated with clinical data in humans to improve patient outcomes. It also highlights the difficulties in doing so.

In brief, the AHRQ creates two parallel paths of evidence for non-human and human models of disease and treatment. Each path moves from the proposed intervention through a target biologic effect to a clinical outcome with compelling evidence required to warrant progress from one step to the next. For an intervention to cross over from non-human to human trials, evidence of "translation" of both target biologic and clinical effects is required. The AHRQ is clear in stating "the relevance of nonhuman (usually animal) models to humans is among the most difficult steps in the framework to satisfy or even to assess." The AHRQ also states "evidence in humans trumps that in nonhuman models."

Phase 1 and 2 clinical trials remain the established vector of integrating new therapies in human populations. ${ }^{2}$ Clinicians seeking evidence that mechanistic therapies "translate" to human populations will find first evidence there. Those same clinicians are sure to see an increased number of such trials as translational research, the movement of mechanistic research from "bench to bedside", is a priority of the National Institutes of Health. ${ }^{3}$ Evaluation of emerging non-human evidence will become easier as work on the registration, ${ }^{4}$ reporting, ${ }^{5}$ and systematic review ${ }^{6}$ of non-human research progresses. In this fast-paced environment, the AHRQ white paper provides a solid framework of weighing and integrating the evidence from all fields of research.

Dr. David Sackett described evidence-based medicine as "the conscientious, explicit, and judicious use of current best evidence in making decisions about the care of individual patients." 7 In the absence of clinical trial evidence, as would be the case with a rare disorder like carcinoid syndrome, application of mechanistic knowledge of disease may well be the "best evidence" available.

Conflicts of interests None declared.

\section{References}

1. Goodman SN, Gerson J. Mechanistic evidence in evidence-based medicine: a conceptual framework. research white paper (prepared by the Johns Hopkins University Evidence-based Practice Center under Contract No. 290-2007-10061-I). AHRQ Publication No. 13-EHC042-EF. Rockville, MD: Agency for Healthcare Research and Quality. June 2013. Available from URL: www.effective healthcare.ahrq.gov/reports/final.cfm (accessed July 2013).

2. Friedman LM, Furberg CD, DeMets DL. Fundamentals of Clinical Trials. 4th ed. New York: Springer; 2010.

3. National Institutes of Health. National Center for Advancing Translational Sciences. Available from URL: http://www.ncats. nih.gov (accessed July 2013).

4. Varga OE, Hansen AK, Sandoe P, Olsson IA. Validating animal models for preclinical research: a scientific and ethical discussion. Altern Lab Anim 2010; 38: 245-8.

5. Kilkenny C, Browne WJ, Cuthill IC, Emerson M, Altman DG. Improving bioscience research reporting: the ARRIVE guidelines for reporting animal research. PLoS Biol 2010; 8: e1000412.

6. Korevaar DA, Hooft L, ter Riet G. Systematic reviews and metaanalyses of preclinical studies: publication bias in laboratory animal experiments. Lab Anim 2011; 45: 225-30.

7. Sackett DL, Rosenberg WM, Gray JA, Haynes RB, Richardson WS. Evidence based medicine: what it is and what it isn't. BMJ 1996; 312: 71-2.

Gregory L. Bryson MD

Department of Anesthesiology, The Ottawa Hospital, Ottawa,

ON, Canada 